\title{
Fault and Short Circuit Analysis for Wind Turbine Generators Grid
}

\author{
${ }^{1}$ Mehdi F. Bonneya and ${ }^{2}$ Ahmed Al-Ameri \\ ${ }^{1}$ Kut Technical Institute, Department of Electrical Technical, \\ Middle Technical University, Baghdad, Iraq \\ ${ }^{2}$ Department of Electronic and Communication, College of Engineering, \\ University of Kufa, AL Najaf, Iraq
}

\begin{abstract}
Competition of short circuit current due to different types of fault that may occur in wind turbine generators grid is interest for many research projects. Under this principle, the emphasis is on the intelligent and fast analysis to prevent damage of equipment and reduce the expensive cost causes by these faults taking into account its nature for working in open areas far from cities. Determine the magnitude of short circuit current at any point of the bas-bar and node of the grid is significantly required to ensure the system reliability and prevent high stress on the equipment. In this research, 8 units of full-convertor variable speed induction generator type is considered by calculating short circuit current for all common of fault kinds. The fault current at each grid sections are computed by using intelligent method based on run length encoding strategy. The results show that the fault at generator terminal cause to huge current and it is very important to use sensitive protection system in order to prevent generator damage.
\end{abstract}

Key words: Wind turbine generator, full-convertor variable speed induction generator, short circuit, fault current, bus-bar, node, power system, fault analysis

\section{INTRODUCTION}

Due to the increasing for electrical energy over the world, wind energy get great interest these days because of its possibility to be one of the main sources for renewable energy which can produce electrical energy taken into account the requirements of sustainable environment and to reduce the emission of heat that resulting from the burning of fossil fuels which causes environmental pollution with the increasing of thermal warming which become a global phenomenon of interest to most of the world. The development in wind turbine generator capacity and also the significant increase in wind turbine power plant, a major trend towards wind energy application, especially in the geographic areas where the wind is continues during the most days of the year (Chakkor et al., 2014).

The research of wind turbines plants is mostly in far areas and is subject to various weather fluctuations and extreme environmental conditions, therefore, these plants need to ensure continuity of work in order to maintain uninterrupted of power and stay connected to the power system grid following the disturbance (Prusty et al., 2016). These criteria can be checked through study most of fault and short circuit conditions that can be occurs during the operation time of plant. Fault analysis for wind systems depend on machine behaviour and model. Two diagnostic techniques has been proposed to detect phase-to-phase fault based on Permanent Magnetic Synchronous Machine (PMSM) by Bouchareb and Nait-Said (2016). Another researcher try to detect fault of rotor for Squirrel Cage Induction Machine (SCIM) by using multi indicator. The simulation and experimental model has been developed with consideration of voltage in neutral and focus on the study different quantities (torque, park and stator currents) that can effect on broken rotor bars (Ouachtouk et al., 2016).

Most of the current researches have been concerned toward wind turbine generators winding and the fault conditions that accompanying to the operation of these generators grid. Time-frequency analysis of power distortion under fault conditions for grid connected wind turbine paper analyses complex investigations of transient conditions in wind turbine power plant using short time Fourier transform (Janik et al., 2007). The performance analysis of fault detection in wind turbine generator based on high-resolution frequency estimation methods is used to improve fault detection and diagnosis to be found in stator current signature depending on super resolution frequency estimation (Chakkor et al., 2014).

Correspoding Author: Mehdi F. Bonneya, Kut Technical Institute, Department of Electrical Technical, Middle Technical University, Baghdad, Iraq 
Practical condition observing and fault identification approach for wind turbine generator is performed by Ahadi (2016) where a continuous monitoring of wind turbine blades are strain acoustic emission monitoring. The quality of electrical power can be directly affected by decreasing short-circuit level of hybrid (wind and solar) energy sources (Misak et al., 2014). Researchers tried to analyses the power quality corresponding to wind speed and solar irradiance in off-grid network. Typical faults with associated diagnosis algorithms are offered and typical faults are classified to three groups according to its effect on wind turbine generator operation. Prusty et al. (2016) study fault analysis for doubly fed induction generator with $\mathrm{AC}-\mathrm{DC}-\mathrm{AC}$ control convertor. Harmonic that generated due to nonlinear loads is compensated by rotor side convertor and the fault analysis is done in order to provide information for the selection of power system components. A novel fault transient equivalence technique based on rotor current peak cloud model is used for doubly fed induction generator by Xu et al. (2017). The parameter combination of the considered model is divided into equivalent wind speed and generator in addition to collecting lines. The effect of random factors such as the fluctuation of wind speed and degree of voltage drop. Zhao et al. (2017) used artificial short circuit test for hybrid wind farm group contains different type of generators. Single and three phase.

The goal of this study is to study the different types of fault analysis on the wind generator system components, this study focuses on fully conversion variable speed induction machine. In terms of fault calculation, analysis has been developed for all grid sectors and all kind of faults. In addition, it provides details on the main factors for short circuit analysis and discussed the main parameters to support power system voltages during the fault.

This study starts with describing the main types of fault on different locations. Next, the most commonly symetrical and unsymetrical components used for short circuit analysis are discussed. Subsequently, the most important results for eight node network is explained based on simulation and wind tubine parameters. Finally, main conclusion are drawn.

\section{MATERIALS AND METHODS}

Pre-fault and short circuit analysis: Any electrical power systems exposed during its operation to different types of fault conditions. Faults occur due to variety reasons including mechanical action where direct contact between the conductors is occur, external and internal over voltage, breakdown of the insulators due to heat, humidity and environmental effects. The computation of short circuit current magnitude in every section of power system is very important specially to ensure the system reliability (De Metz-Noblat et al., 2005). The abnormal fault current values put an important stress on the power system components and consider as important factor to select appropriate power system equipment.

Types of fault: Most of fault accident is one or more of the following cases:

. Three-phase fault

- Line to line fault where any two phases short together

Line to line to ground fault

Single line to ground fault

The accurateness of fault current calculation depend on the system configuration and modeling accuracy. In this research all of the above faults are analyses and short circuit current is determine for the wind turbine power plant under consideration and the wind speed is in transient condition and the impedances value is increased from minimum value taken at subtransient X" transient X.' and steady state value $\mathrm{X}$. For induction generator, the rate of increase is more than that for synchronous generator (Lackovic, 2012).

If you want to use bullets in your text, use only the itemize environment, the enumerate environment is not supported by the editorial staff. If the enumerate environment is used, the Layout editor will automatically change it into the itemize environment. The editorial staff supports only the first and the second indentation level.

When a fault occur at any section of wind power plant a short circuit current is developed and this current is calculated by using symmetrical component technique. This technique is used for all types of radial system at all voltage levels. By using superposition theorem, the fault current can be calculated and the positive, negative and zero components can be shown as Lackovic (2012), Jeon et al. (2011):

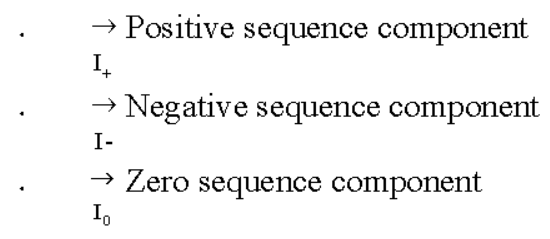

The following operator is used between the above three components Eq. 1:

$$
a=e^{j \frac{2 \pi}{3}}=-\frac{1}{2}+j \frac{\sqrt{3}}{2}
$$

The short circuit current for the three phase is computed using the Eq. 2-4: 


$$
\begin{gathered}
\overrightarrow{\mathrm{I}}_{1}=\overrightarrow{\mathrm{I}}_{+}+\mathrm{aI}_{-}+\overrightarrow{\mathrm{I}}_{0} \\
\overrightarrow{\mathrm{I}}_{2}=\mathrm{a}^{2} \overrightarrow{\mathrm{I}}_{+}+\mathrm{a} \overrightarrow{\mathrm{I}}_{-}+\overrightarrow{\mathrm{I}}_{0} \\
\overrightarrow{\mathrm{I}}_{0}=\mathrm{a}_{+}+\mathrm{a}^{2} \overrightarrow{\mathrm{I}}_{-}+\overrightarrow{\mathrm{I}}_{0}
\end{gathered}
$$

The symmetrical current components are related to the symmetrical voltage components and equivalent impedances values which are defined for various system component by the manufacturers. The symmetrical current component and also that for voltage component are related by the equivalent impedance components Eq. 5:

$$
Z_{1}=\frac{V_{1}}{I_{1}}, Z_{2}=\frac{V_{2}}{I_{2}}, Z_{0}=\frac{V_{0}}{I_{0}}
$$

Fast power flow calculation: The short circuit analysis required the power flow calculation to determine the pre-fault voltages. In this study, the real time monitor of grid based on load flow calculation with less competition time has been considered. This method based on run length Encoding method (data decompression method) that was presented by Al Ameri et al. (2014). The jacobian matrix has been reconfigured to optimize the number of iteration to the exact number required.

This proposed method has been tested for different standard IEEE bus systems to compared results to prove its efficient. The algorithm was started by read input data to build vector instead of 2 dimension matrix which represent the tree of connection between buses. The method was consider counter to determine the total of lines connect to each bus and the index of buses represented by index of rows. This structure re-arranged the data of matrix as only one vector include all data of row's matrix.

In general, the RLE algorithm consist of dictionary that occur in the data of input while the output is represent the index number of data in the dictionary. The dictionary algorithm has been explained in Fig.1.

Case study: To verify the fault analysis in a wind turbine grid, the mesh network consist of 7-bus has been modelled. The wind turbine plant under consideration consist from 8 full-convertor variable speed induction generator is shown in Fig. 2. It included 7 buses, a slack generator (represented as a reference bus on bus N21), 8 generators (represented as a wind turbine connected on buses 2, 5, 7, 12 and N17).

The short-circuit analysis method has been proposed based on the following assumptions; the rated capacity of each wind generators is set $1.75 \mathrm{MW}$. The data of the

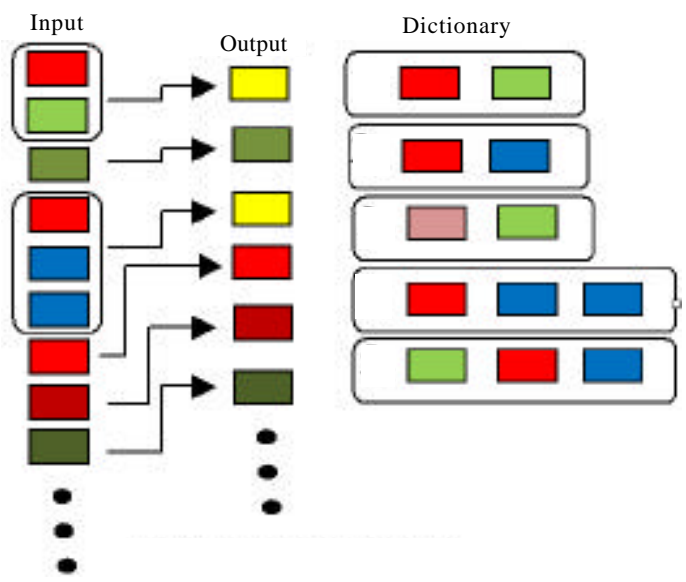

Fig. 1: Dictionary algorithm

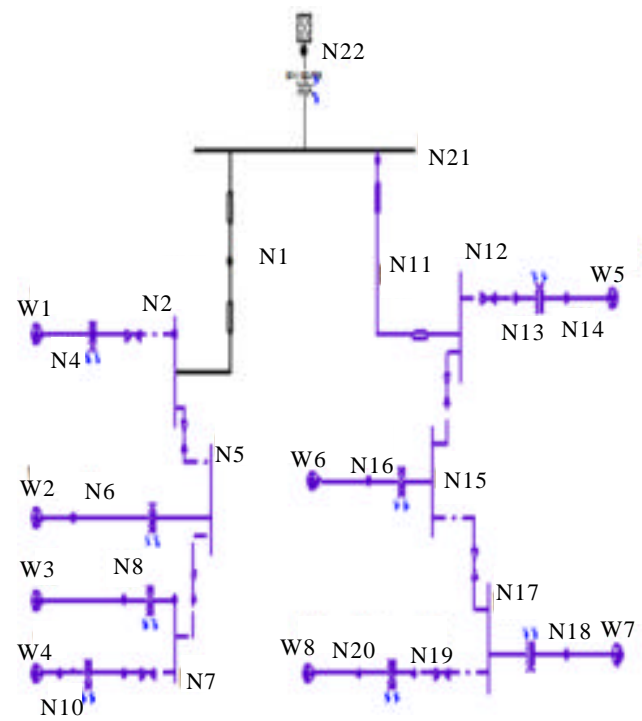

Fig. 2: The 7-bus test system

Table 1: Wind turbine generator data

\begin{tabular}{ll} 
Generator data & Values \\
\hline Apparent power & $1750(\mathrm{kVA})$ \\
Rated voltage & $570(\mathrm{~V})$ \\
Frequency & $60(\mathrm{~Hz})$ \\
Active power & $1500(\mathrm{~kW})$ \\
Rated current & $2450(\mathrm{amp})$ \\
Speed & $1800(\mathrm{rpm})$ \\
No. of poles & 4 \\
Power factor & 0.90 \\
Efficiency & $97(\%)$ \\
Moment of inertia & $25.0\left(\mathrm{~kg} \cdot \mathrm{m}^{2}\right)$ \\
\hline
\end{tabular}

wind turbine generators has been detailed in Table 1 and all units has been convert to p.u. based on rated power and voltage.

The transformers were configured as grounded wye-grounded wye and all of the balanced loads were delta configuration. All the initial generators voltages were set to $1.0 .0^{\circ}$ p.u. and reference frequency was $50 \mathrm{~Hz}$. 


\section{RESULTS AND DISCUSSION}

Short circuit test is performed at all node connections for most types of fault. The distances between the main bus-bar $(230 \mathrm{kV})$ that its connected to the network grid and sub bus-bars and nodes are shown in Fig. 3 where the distance reach to $9500 \mathrm{~m}$ for five generators.

L-L-L fault applied on all plant nodes (22 nodes), the short circuit current at all generators terminal variation from 26426-27609. A depending on the distance that shown above. The less short circuit current is at node $22(230 \mathrm{kV})$ bust. Figure 4 explain short circuit fault results.

Knowledge of short circuit at every section of the network is very important in order to insure system reliability. The huge value of current caused by the fault put an effective stress on the electrical apparatuses and if its not in a properly rated it may cause to apparatuses damage.

Short circuit competition for L-L-G fault for all of wind turbine grid is shown in Fig. 5. The generators fault current is more than that for L-L-L fault and this is due to the connection of stator winding (star with neutral point

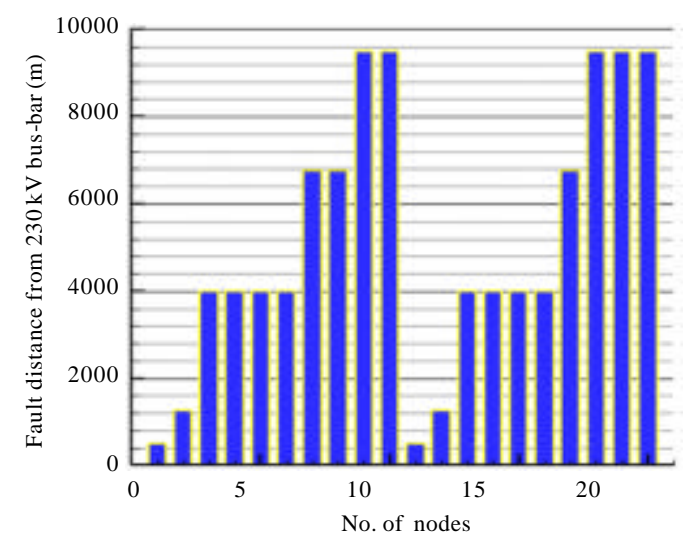

Fig. 3: Fault distance at each node against node number research

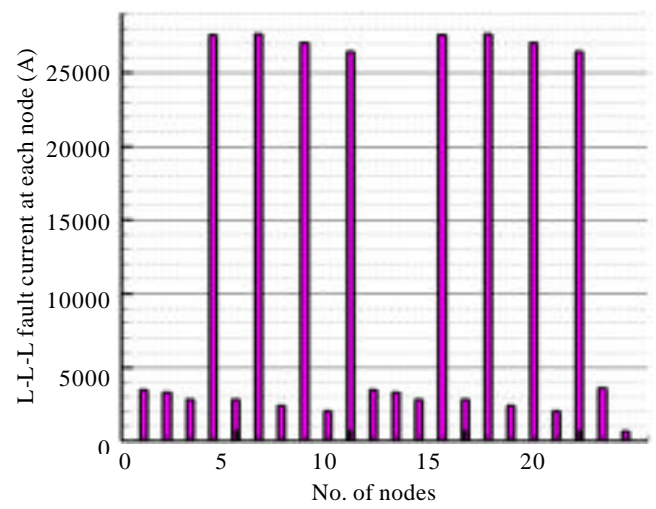

Fig. 4: Short circuit current at each node with L-L-L fault while the other sections fault current is reduced. For $\mathrm{L}-\mathrm{L}$ fault, the generator fault current is less than that for the above faults as demonstrated in Fig. 6. The last kind of fault is L-G where the generator fault current is more than that for the other fault types and the reason is also due to the connection of the stator winding. Figure 7 explain the current in all the grid sections.

Different kinds of fault is analyzed at some of generators terminals and compute the fault current at each network nodes. Figure 8 show that the fault current at each system nodes and the current reach its maximum value $(25291 \mathrm{~A})$ at the faulted generator No. 7 and reduced gradually at node $11,12,15,17,21$. The lowest fault current values is at the node $3,7,9,13,19$.

The contribution fault current for each generator when the fault occur at generator 7 is shown in Fig. 9 where the neighboring generators $5,6,8$ contribute with the largest values.

The same think is shown when the L-L-L fault at generator 2 terminal and the contribution is from the neighboring generators $1,3,4$. Figure 10 displayed these contribution.

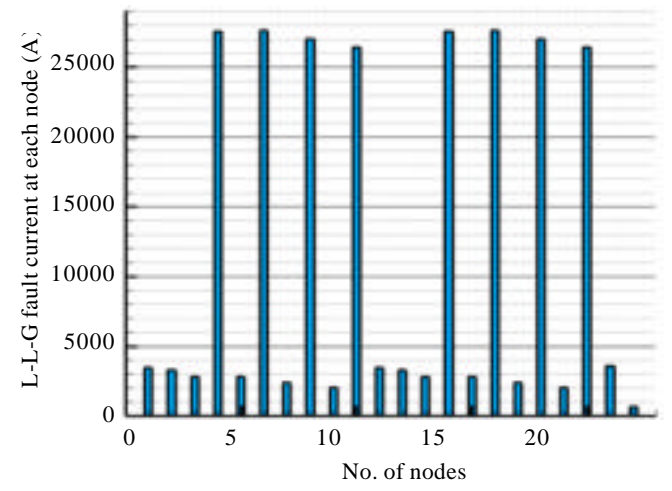

Fig. 5: Short circuit current at each node with L-L-G fault

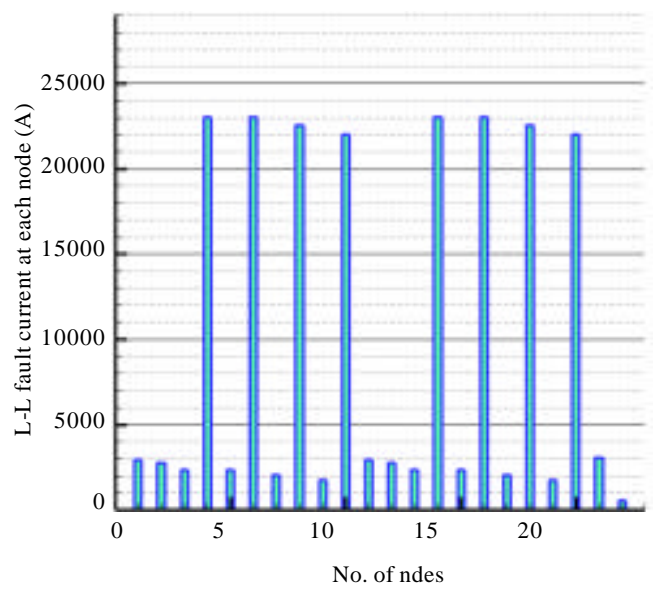

Fig. 6: Short circuit current at each node with L-L fault 


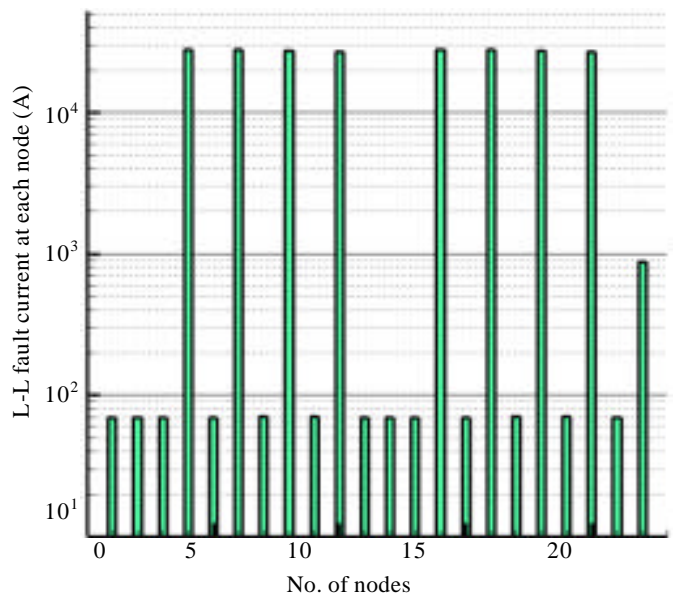

Fig. 7: Short circuit current at each node with L-G fault

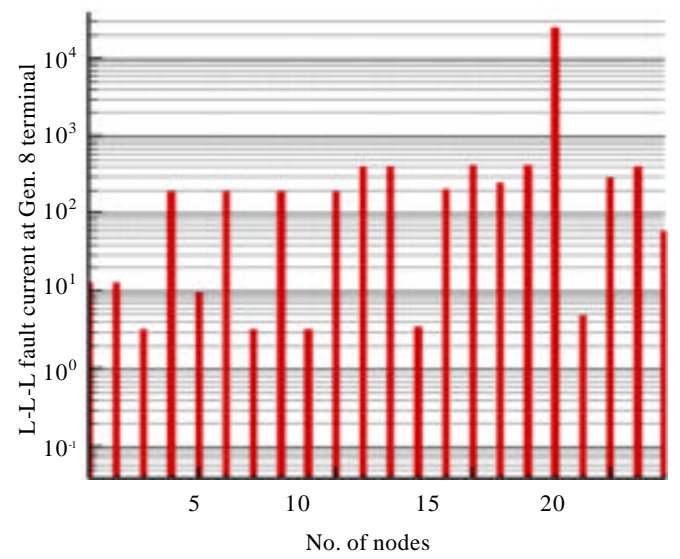

Fig. 8: L-L-L fault current at Gen. 7 terminal

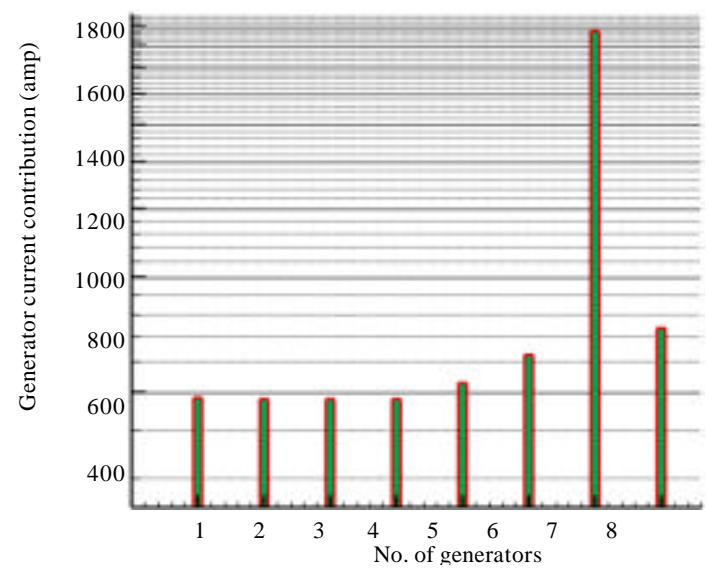

Fig. 9: Gen. crrent contribution during L-L-L fault at Gen. 7

The second kind of fault that considered for wind turbine generator is L-L-G where this fault is less effect then the above fault. As is 8 generator, so for, each fault one of these generator is selected to the faulted one of

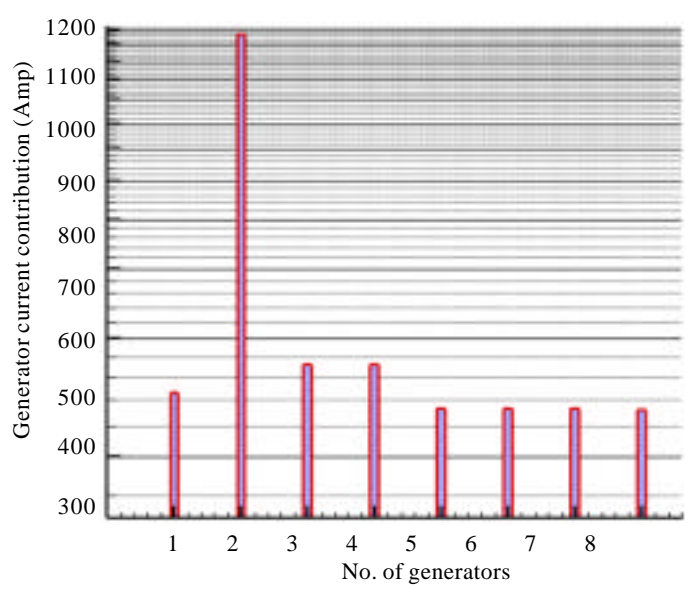

Fig. 10: Gen. current contribution during L-L-L fault at Gen. 2

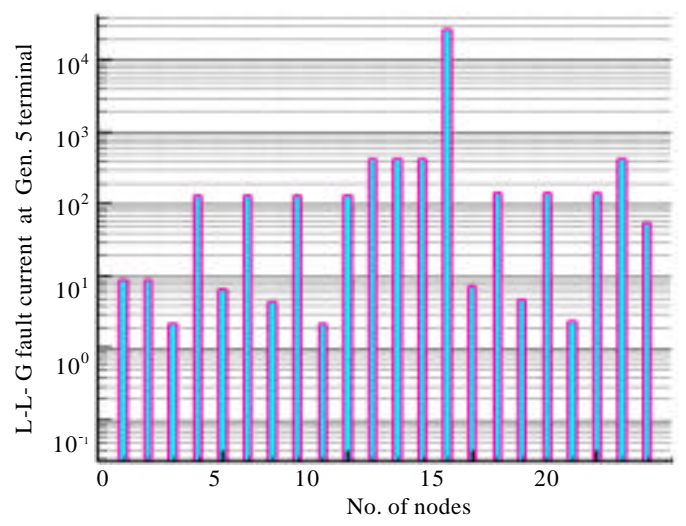

Fig. 11: L-L-G fault current at Gen. 5 terminal

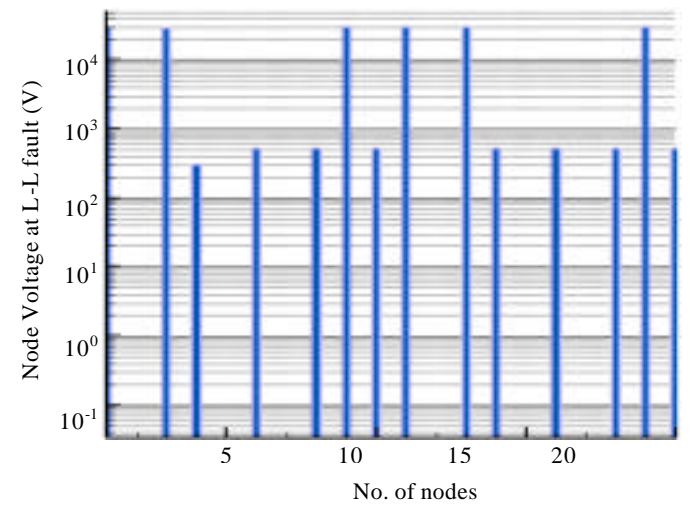

Fig. 12: Voltage at each node during L-L fault at Gen. 1

them. This fault is considered to be occur at terminal of generator 5. The fault current at each node of the plant is show in Fig. 11 and 12 where the most fault current is from generator 5 and the contribution from neighboring generators is more than form far generators. 


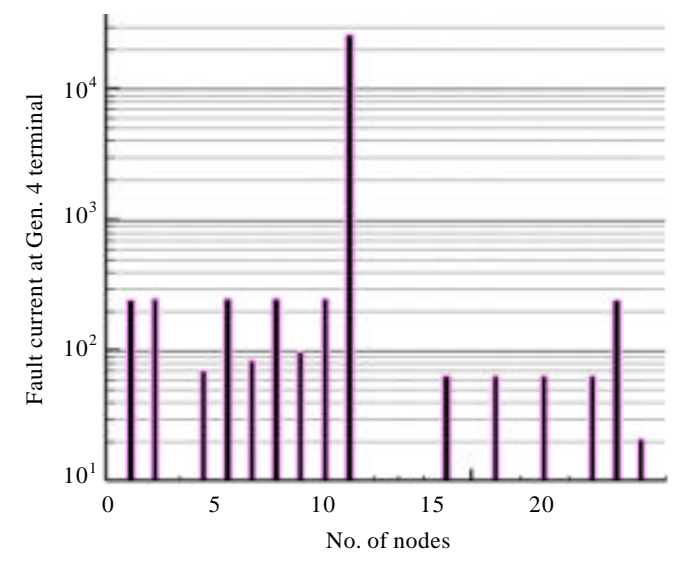

Fig. 13: Voltage at each node during L-G fault at Gen. 4

$\mathrm{L}-\mathrm{L}$ fault is applied on generator 1 terminal where the fault current is similar to L-L-G with minor difference than that for L-L-G fault. The voltage at plan node during fault duration is shown in Fig. 12. The final fault that applied to the network is $\mathrm{L}-\mathrm{G}$ fault applied on generator 4 where the most fault current is from the faulted generator. Figure 13 shown the fault current for the node of the system.

\section{CONCLUSION}

Fault analysis is one of the most important analysis for any power system (especially wind turbine generators grid) in order to determine short circuit current. The size of system component can be defined according to fault analysis in order to insure reliable operation at any sever condition. In this research the short circuit current at all bus-bar and nodes is determined, also, the effect of different types of fault at most of system under consideration. From the obtained results its clearly shown that the huge fault current is when the fault is occur at the generators terminal specially for L-L-G and L-G and this is due to the star with neutral connection of generator stator winding. So that, it is very important to used very sensitive protection system and select rigid components due the expensive prices for wind turbine generator and the difficulties of maintenance.

\section{ACKNOWLEDGEMENT}

This research is financed by Middle Technical University and University of Kufa to support the researches in the field of renewable energy resources.

\section{REFERENCES}

Ahadi, A., 2016. Wind turbine fault diagnosis techniques and related algorithms. Intl. J. Renewable Energy Res., 6: 80-89.
Al Ameri, A., C. Nichita and B. Dakyo, 2014. Load flow calculation for electrical power system based on run length encoding algorithm. Proceedings of the International Conference on Renewable Energies and Power Quality (ICREPQ), April 8-10, 2014, Cordoba, Spain, pp: 7-10.

Bouchareb, C. and M.S. Nait-Said, 2016. PMSM Model with phase-to-phase short-circuit and diagnosis by ESA and EPVA. Adv. Electr. Electron. Eng., 14: 522-530.

Chakkor, S., M. Baghouri and A. Hajraoui, 2014. Performance analysis of faults detection in wind turbine generator based on high-resolution frequency estimation methods. Intl. J. Adv. Comput. Sci. Appl., 5: 139-148.

De Metz-Noblat, B., F. Dumas and G. Thomasset, 2005. Calculation of short-circuit currents. Master Thesis, Schneider Electric, Rueil-Malmaison, France.

Janik, P., T. Lobos, J. Rezmer and T. Sikorski, 2007. Time-frequency analysis of power distortion under fault conditions for grid connected wind turbine. Proceedings of the 2007 International Conference on Clean Electrical Power, May 21-23, 2007, IEEE, Capri, Itlay, ISBN:1-4244-0631-5, pp: 741-746.

Jeon, J., J. Son, M. Lee, Munkbaht and D.S. Rho, 2011. A study on fault analysis of wind power (DFIG) in distribution systems based on the PSCAD/EMTDC. Proceedings of the International Conference on Grid and Distributed Computing, December 8-10, 2012, Springer, Berlin, Heidelberg, Germany, ISBN:978-3-642-27179-3, pp: 59-66.

Lackovic, V., 2012. Introduction to short circuit current calculations. Master Thesis, Continuing Education and Development, Inc., Stony Point, New York, USA.

Misak, S., J. Stuchly, L. Prokop and M. Uher, 2014. Power quality analysis in off-grid power platform. Power Electr. Eng., 12: 177-184.

Ouachtouk, I., S. El Hani, S. Guedira, K. Dahi and L. Sadiki, 2016. Advanced model of squirrel cage induction machine for broken rotor bars fault using multi indicators. Adv. Electr. Electron. Eng., 14: 512-521.

Prusty, B.K., C.K. Panigrahi and S.M. Ali, 2016. Study of fault analysis in a doubly fed induction generator wind energy conversion system. Intl. J. Eng. Sci. Emerging Technol., 9: 9-17.

Xu, H., P. Zhao, Y. Zhao, X. Wei and J. Liu et al., 2017. An equivalent method for the fault circuit current analysis of DFIG wind farm. Proceedings of the 2017 China International Conference on Electrical and Energy (CIEEC), October 25-27, 2017, IEEE, Beijing, China, ISBN: 978-1-5090-6277-5, pp: 343-350.

Zhao, P., J. Jia, R. Wang, F. Luan and P. Yu et al., 2017. Analysis of short circuit characteristic of hybrid wind farm group based on artificial short circuit test. J. Eng., 2017: 1692-1695. 